\title{
Presentation
}

\section{Thematic section: School and Educational Psychology - Challenges of professional practice and research in different educational contexts}

Having a space in a Psychology journal specifically devoted to address issues, questions, findings, and concerns about the professional practice and research in the field of School and Educational Psychology is, on the one hand, a great opportunity to consolidate this area which, from a critical perspective, has been meeting the demands presented by different educational contexts; on the other hand, it is an opportunity to pose questions and challenges faced by professionals who develop activities and carry out studies in schools, universities, and government institutions, since education and barriers to education, especially with respect to the desired performance of children, youth, and adults, has become a top priority topic.

Aiming at stimulating reflection and discussion about ways to meet the challenges inherent in the training and education of Psychology or Basic Education professionals, in the professional practice of school psychologists counseling children, youth, or adults, and in research, especially with regard to research methods, we selected the articles that make up this thematic section hoping to shed light on the factors associated with demands of the professional practice and role of researchers, teachers, professors, and psychologists.

The introductory article, by Feliciano H. Veiga (University of Lisbon, Portugal), Viorel Robu (Petre Andrei University, Romania), and Adriana Ortiz (National University of Salta, Argentina), presents a discussion of studies on the relationship between student engagement in school and family contexts, demonstrating that different contexts significantly influence this relationship, providing important elements for understanding the role of the family in children's school performance.

The second article, also theoretical, by Claisy Maria Marinho-Araujo (University of Brasilia), addresses School Psychology in higher education as an innovative experience, proposing a practical model consisting of five main areas: Institutional Mapping; Psychological Listening; Management of Policies, Programs, and Educational Processes; Pedagogical Proposals and Course Design; and Student Profile, making a valuable contribution to the professional practice in this educational stage.

The article by Walter Mariano de Faria Silva Neto (University of Uberaba) and Raquel Souza Lobo Guzzo (Pontifical Catholic University of Campinas) discusses school psychologist education, investigating the practices of supervised internship, especially the training and education of supervisors. The authors highlight the need for reassessing internship practices since they are the main professional training of those that will work in educational settings. Another article, by Fabiola de Sousa Braz Aquino and Jessica Andrade Albuquerque (Federal University of Paraíba), also addresses internship in School Psychology as part of professional education. The authors investigated a supervised internship program based on the Theory of Historical-Cultural Psychology.

With regard to School Psychology practices, Eliseu de Oliveira Cunha, Maria Virginia Machado Dazzani (Federal University of Bahia), Gilberto Lima dos Santos (Bahia State University), and Patrícia Carla Silva do 
Vale Zucoloto (Catholic University of Salvador) analyze the dynamics of perceptions of school-related problems among teachers, pedagogical coordinators, and health professionals working in child health services.

The penultimate article, by Lilian Aparecida Cruz Dugnani and Vera Lucia Trevisan de Souza, (Pontifical Catholic University of Campinas), addresses the contributions of psychology to bring about changes in school management practices, presenting different school psychologist approaches for working with the management team members, based on the conception that they are responsible for changes in the pedagogical practices and school relationships. The thematic session ends with the article by Wanda Junqueira de Aguiar and Virginia Campos Machado (Pontifical Catholic University of São Paulo), which addresses the importance of producing knowledge to understand the subjective aspects of teaching practice based on theoretical assumptions of Socio-historical Psychology.

These scientific reports in the field of School Psychology broaden the discussions that have been held in different channels and forums and consolidate it as an area of professional practice of psychology and as a research field, which can greatly contribute to improve the provision of education in our country.

Vera Lucia Trevisan de Souza Associate Editor Pontifícia Universidade Católica de Campinas, Centro de Ciências da Vida, Programa de Pós-Graduação em Psicologia como Profissão e Ciência 